\title{
Living a good life?: Considering technology and pro-social behaviour
}

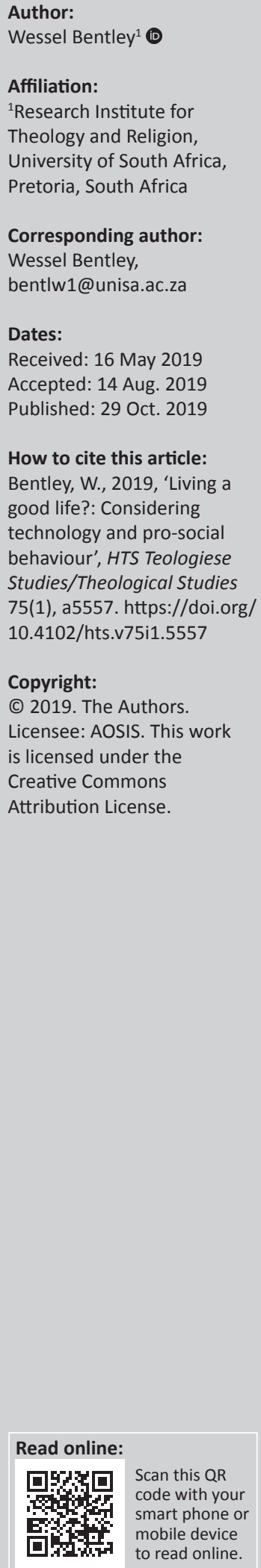

This article explores the notions of a good life as understood in religion and psychology. The markers of altruism and empathy are identified. The effect the use of social media has on brain chemistry is then explored and used in trying to answer the question as to whether technology (social media in particular) is hampering our ability to live a good life. The notions of the rise of narcissism and the decline in empathy are also discussed.

Keywords: Psychology; Religion; Social Media; Empathy; Narcissism.

\section{Introduction}

When we embarked on a project of writing a prescribed textbook for first-year Christian ethics students, we decided on the title 'What is a good life? An introduction to Christian ethics in 21st century Africa' (Kretzschmar, Bentley \& Van Niekerk 2009). The question as to 'What is a good life?' is not new. In our quest to find an answer, we went as far back as Aristotle, who described a good life as a life in pursuit of happiness. This truth has largely informed the West of what could be regarded as a good and wholesome life. The misconstrued interpretations of this philosophy have had dire consequences for this planet and are plain to see. Also, we are African, and although Aristotle and the Western ethical frameworks may be helpful in our search for an answer to the posed question, we must (more importantly, we are compelled to) learn from African philosophy and ethical frameworks. Richardson (2009:44-53) then drew our attention to five features of African philosophy that serve as measures of a good life. These are the following: ${ }^{1}$

- Holism: That there are no dualities or dichotomies, but that life is a complete whole and therefore goodness needs to permeate all aspects of one's being. Goodness is not only a spiritual exercise, influencing the body, but also is a state of being and a life lived in relationship.

- Vitalism: Life energy enhances one's ability to live a good life, and therefore a person should participate in life-giving activities, traditions, rituals and relationships.

- Communality: A person does not live as an isolated individual, but forms part of a greater whole, a community. Being in community makes one a good person.

- Relationship with ancestors: One's goodness is linked to one's community, even beyond this life. Accountability is communal.

- Ubuntu: A philosophy that states that the person is only a person through others and hence goodness is measured in terms of one's upbringing, belonging and contribution to the community as a whole.

It has been 10 years since we published the book. In the meantime, the world - especially how we experience community - has seen a tsunami of change. Some of the reasons for this include the rise in the use of personal devices to communicate, the emergence of social media platforms and the ever-growing phenomenon of creating a personal identity online that serves as a person's presence both in the physical and in the cyberworld. The question that beckons is: is technology having an impact on what we perceive to be the markers of living a good life? In this article, I will describe common markers found in religion and psychology of what can be seen as a good life; present the findings of research performed on brain chemistry and the use of personal devices and the effects it has on human behaviour; and conclude by proposing mediating actions that can ensure that the use of personal technology devices (social networking platforms in particular) do not come at the cost of what we consider to be a good life.

1.These are short summaries of the main points Richardson describes in his chapter.

Note: SASRF 2019, sub-edited by Cornel du Toit (University of South Africa) and Wesel Bentley (University of South Africa). 


\section{So, what can be considered to be a good life?}

\section{A broad view from religion}

May I suggest that this question is one that concerns our traits as beings with our propensity for both moral behaviour and religious awareness. Broom (2006:20-21) claims that morality is an evolutionary development that minimised harm and enhanced collaboration between individuals and groups. Recent studies have shown that this is not unique to humans, but seems to be present in many other species of life as well. The extension of what can be deemed as the existence of moral codes in species other than human is currently being studied by the leading scholar Frans de Waal, who is revealing significant findings. His research will not be described here but is well worth following.

The phenomenon of creating moral frameworks then led to the normalisation of specific behaviours, attitudes and interactions that resulted in a distinction being made between what is considered to be (socially) good and evil. That which differentiates humans from other species, according to Broom, is that humans have formalised these moral codes in the shape of religion, extending these codes to levels that transcend the immanence of their existential experience of life. A critical question can be posed, asking: 'If religions stem from evolutionary developments in the human desire for effective functioning, then why do we find that so many religions compete against one another?' Surely, religions with the common desire to facilitate 'a good life' will see the value in religious expressions other than their own. Atran and Heinrich (2010:18-30) argue that once moral codes have given birth to religious expressions, these faith-based belief systems develop distinct rituals that increasingly create an in-group identity that will, on the one hand, not only strengthen pro-sociality within this group, but also increase between-group enmity.

Moral codes, or the different interpretations of what is a good life then become a competitive space, with each expression vying for their truth to be universalised and accepted as the most correct answer to the stated question (what is a good life?). The rise of New Atheism has criticised the role of religion in society, portraying it as being nothing more than a deceptive power that aims to control and manipulate social thinking, and thus cannot be a trustworthy platform for either describing or facilitating a good life. Should we, or can we then do away with religion and settle on a common moral code, devoid of transcendental presuppositions? Boyer (2008), Professor of Psychology and Anthropology at Washington University, states that although this may be an intriguing notion, there is a string of cognitive traits in human beings that predispose us to faith, which, in turn, leads us down the path of formalised religion.

Despite the fact that so many religions exist, and that so many find themselves in competition with (and even in opposition against) one another, movements like the United Religions Initiative is doing work among diverse communities in emphasising the commonality that can be found in different faith expressions. ${ }^{2}$

According to their message, it seems as if the United Religions Initiative argues that if we take away the transcendental aspect of different religions, a central theme of altruism can be considered as a distinct marker in identifying a (religious and) good life. A person will be considered to live a good life if they are able to move beyond the interests of self and extend their innate drive for personal prosperity to the well-being of others. It is interesting that some religions such as Janism even include other creatures and not only other humans. A good life is a life that is good for all, and not only for self. It needs to be noted that the transcendental nature of religion cannot simply be muted to make a certain point. Religions on their own would argue that it is in the transcendental nature of religion that we find a motivator for altruism.

From my perspective as a Christian theologian, the teachings of the faith tradition that I belong to certainly resonate with the idea that a good life entails acts of altruism. In the Ten Commandments, for instance, while the first four commandments focus on one's relationship with God, the remaining six deal with the manner in which one engages with others. When Jesus speaks about the outworking of one's faith in Matthew 25:35-40, Jesus focuses on practical, altruistic actions, namely, to feed the hungry, to give the thirsty something to drink, to welcome the stranger, to clothe the naked, to care for those who are ill and to visit the incarcerated. In Acts, chapter 2, we find that the early church spent their time, energy and resources in sharing their possessions with those in need, being in fellowship with one another, sharing meals (and Communion) with one another and worshipping together. By this, 'the Lord added to their number those who were being saved' (Ac 2:47 NRSV). One may argue that this emphasis on altruism may lead to a theological position that proposes a 'salvation by works'. John Wesley, in his sermon Salvation by faith, argues that while this may be a perspective held in some Christian circles, the order of salvation that we experience speaks against this notion. We do not do altruistic deeds to convince God of our eligibility for salvation. No, it is because we experience God's gift of salvation that we, in turn, manifest good deeds as an expression of our response in faith to God. Altruism is an external, but local expression of a love for God, a God who calls us to love our neighbour as we love ourselves.

\section{A view from psychology}

From the perspective of behavioural psychology, the human capacity for 'being good' is the human propensity (and goal) to conform to social norms that define what is acceptable behaviour. Altruism naturally contributes towards this kind of life. 'Abnormal behaviour', or behaviour outside the norm, would include behavioural characteristics that are mostly not deemed acceptable within either the personal or social spaces of an individual or group. Although the DSM-5 (Diagnostic and Statistical Manual of Mental Disorders) 2.For a thought-provoking summary, see Davcevski (2017). 
criteria for mental (and includes behavioural) disorders serve as an instrument to diagnose disorders that fall outside the mean of human characteristics and behaviour, it is not enough to gauge whether a person is living a good life or not. For instance, it is impossible to say that a person who has a learning disorder or who experiences depressive disorders can be classified as not living a good life, simply because they vary from the norm. On the contrary, when psychological disorders impact in a harmful way to self and others, for instance, paedophilia, narcissistic personality disorder or partner abuse (violent and emotional), society does not look kindly to this behaviour, and cannot classify these as standards to be emulated.

Normative behaviour tends to describe healthy personal functioning in light of one's capacity to contribute and receive from one's social context. Of course, these are very broad strokes, and behavioural psychology is much more nuanced, depending on the form of behaviour observed. If one were to attempt to find a common factor in pro-social behaviour, in the transaction of both contributing and receiving from one's social context, then empathy plays a vital role. Keysers, in his book entitled The emphatic brain (Keysers 2011), states that the human brain is wired for emotional connection with other people, and it is this drive and ability that makes us distinctly human (Keysers 2011:8-9). In fact, socially speaking, the success of careers and relationships largely depends on our ability to 'read the emotional states of others' (Keysers 2011:9), which requires a level of empathy to be present. Empathy is therefore also a marker for a well-adjusted and socially integrated person. We will see later in this article that empathy is a trait that lacks in psychological disorders such as narcissism.

Psychology then asks the question: are the traits of altruism and empathy determined by 'nature or nurture'? In other words, are these traits of what can be considered to be a good life learnt or are they innate to us as human beings? To what extent is our genetic make-up responsible for us being 'good' or 'evil'? If we can be genetically predisposed for actions that do not carry the approval of social norms (such as theft, murder and so on), then we are faced with ethical questions regarding the way society deals with holding people accountable for 'bad' behaviour. Although there is evidence of genetic propensity for certain criminal and antisocial behaviour (see Wertz et al. 2018), it has been widely accepted that 'good' and 'bad' behaviours are to some extent learnt. The process of mimicking is part of the way in which human behaviour and learning are shaped (Baron, Byrne \& Branscombe 2005:390-393). Pro-social behaviours such as altruism and empathy are key learnt behaviours that are indicative of being a good person (see Baron et al. 2005:393-400), which, in turn, leads a person to have moral integrity and the internalised conviction that they form part of a system greater than themselves.

The link between empathy, altruism and pro-social behaviour was formally linked to neurocognition in studies conducted by Fogassi, Gallese and Rizzolatti in 1990 with their discovery of mirror neurons (see Gallese, Eagle \& Migone 2007; Keysers 2011:13). Mirror neurons refer to the firing of the same neurons in the brain whether an animal (or person) acts or observes the same action performed by another. The discovery was made by observing the brain function of a monkey when it grasped a raisin and comparing it to its brain function when it observed another monkey taking a raisin. Fogassi, Gallese and Rizzolatti found that the same parts of the brain became active, and not only the temporal visual cortex, as was expected. 'It was as if the monkey was pretending to do the action it was observing' (Keysers 2011:14). Further studies have shown that repetition of certain actions and experiences increases the individual's capacity to anticipate responses when performed by others (Gallese et al. 2007:146-148). Not only do mirror neurons enable us to anticipate and feel the actions of others, but also our ability to mirror anticipated emotions in others has been proven. Iacoboni (2009) showed that there is a distinct connection between imitation, mirror neurons and empathy. Experience, action and interaction lead to what is termed theory of mind; being aware of, assuming, anticipating and mimicking what one deduces another person is feeling, experiencing or thinking. It is this empathic trait that leads to pro-social behaviour such as altruism, making empathy and altruism not only actions aimed at self-preservation but also traits that enhance the common good (De Waal 2008).

It would be fair to suggest that the two markers of a good life important to both religion and psychology are altruism and empathy.

\section{(Personal) Technology and its impact on humanity}

The question as to whether technology can enhance human morality is widely contested. Philip Clayton argues that while technology itself is ethically neutral, the use and application of technology may not be (Clayton 2011:131-134). I agree with this proposition. The same technology that makes it possible for certain cancers to be treated may be used in atomic warfare to cause death and destruction. Similarly, the use of personal devices such as cell phones and the accompanying social media platforms used on them have, on the one hand, made the world a much small place, with events like the Arab Spring being broadcast at the push of a button, while, on the other hand, are causing numerous relational problems. To make a generalised judgement of whether technology is inherently evil or a causal source of evil would be nonsensical. To state that personal technology is good in an absolute sense would be equally unfair. Of course, there are positives and negatives associated with personal devices and the use of social media. The aim of this article is not to weigh up the benefits and disadvantages of these, but to simply ask what effect these instruments may have on our behaviour.

In an important study, Alloway et al. (2014:150) state that the use of social networking sites has led to significant changes in the nature of our social relationships. Two notable shifts can 
be observed, namely, the one negative and the other positive. The first is that those who often engage in social networking platforms tend to have an increased focus on self, with selfpresentation and self-promotion becoming the primary motivator for their use of this technology. The second is that those who engage in technology that facilitates 'Live chats' present an increase in perspective taking and may increase social connection and empathy (Alloway et al. 2014:156).

Regarding the first shift, numerous studies are showing a connection between the use of social networking sites and the rise of narcissism. ${ }^{3}$ In a study that assessed the use of Twitter and Facebook among college and adult populations, the following reasons were given for their respective use of these platforms (Davenport et al. 2014:218):

\section{For Facebook:}

- The user can stay up to date with current events and is able to share information.

- The user wants Friends.

- The user seeks affirmation and admiration from their friends.

\section{For Twitter:}

- The user can stay up to date with current events and is able to share information.

- The user wants Followers.

- The user seeks affirmation and admiration from those who follow them.

As can be seen, the focus is on the user, their affirmation and their popularity. The study concluded that in the use of social media, the goals in the use of these platforms soon became the building and maintaining of a person's online profile and may promote hedonistic and narcissistic behaviour. One may ask whether it is true that there is a causal link between the use of social media and the rise of narcissistic behaviour or whether it is just a case of narcissists ${ }^{4}$ being drawn to and being more prone to use social media.

It can be commonly accepted that not everyone who uses social media technology becomes a narcissist or is a narcissist! The findings of these studies are, however, noteworthy. Leung (2013) presents a somewhat different argument. Leung states that people who show exhibitionist tendencies are more drawn to the allure of the self-promoting nature of social media platforms, but that it should be considered that there is also a substantial generational difference in the way young people engage with social media, compared to their older compatriots. To Gen-Exers and Net-Geners, social media is a part of the world in which they live; an indispensable instrument for self-expression,

3.In this field the American research psychologist Jean Marie Twenge is doin groundbreaking work, not only identifying a marked increase in narcissism, but also depressive disorders in younger generation users of social media platforms.

4.One needs to be very careful in using terms like 'narcissists', as narcissism is a distinct behavioural disorder that needs to be diagnosed by a professional in psychology or psychiatry. The use of the term in these studies indicates a clinical diagnosis by those who conducted the studies. discussion, interaction and gaming (Leung 2013:1004). This generation of young people finds it hard to imagine a world where they do not have a cyber presence or have the availability of information literally at their fingertips. Studies at the University of Würzburg (2017) have found that although younger generations may have this almost inseparable bond with their personal devices (and social media in particular), it does not mean that all is well in their interpersonal relationships. The focus on self and the promotion of one's own online identity, awaiting online affirmation and recognition, is a self-reinforcing cycle that breaks down the interpersonal skills that are required in becoming well-adjusted adults with pro-social behaviour (University of Würzburg 2017).

It is alarming that there has been a marked increase in negative social behaviour among young people, with particular reference to the use of social media technology as an instrument for cyberbullying. In longitudinal studies by Heirman and Walrave (2008), it was found that cyberbullying among young people increased by as much as $50 \%$ between 2000 and 2005 (Heirman \& Walrave 2008), and that the numbers are rising. Brochado, Soares and Fraga (2017) show that there has been a threefold increase in reported cases of cyberbullying between 2011 and 2012 alone, compared to their data from 2010. In their popular book, The narcissism pandemic, Twenge and Campbell (2009) illustrate how younger people are showing and increasing emotional detachment to those around them while having a marked increase in their views of self. These traits, they argue, are being reinforced (not necessarily caused) by their use of social media platforms and information technologies (Twenge \& Campbell 2009:299-303).

Studies are also showing that for those who participate in negative social behaviour such as cyberbullying, it is easier to engage online than to participate in physical forms of bullying. Heirman and Walrave (2008) argue that this is true for the following reasons:

- These technologies allow for a certain level of anonymity.

- These technologies give a bully $24 / 7$ access to the victim and vice versa.

- There is a lack of non-verbal communicative feedback (cues) that help moderate behaviour. 'Seeing tears, shaking heads, staring eyes, a frown, a bored expression and other more or less subtle face-to-face-cues can slam the breaks on what people are saying or doing' (Heirman \& Walrave 2008:6).

I would argue that this last point is of particular significance in the changing negative behaviour associated with the use of these technologies. It may be that these technologies, by creating physical distance between people, may deprive users of cues that will promote within themselves and in their interpersonal relationships, the traits of empathy and altruism. Altruism and empathy, as stated earlier, are learnt behaviours, best reinforced with person-to-person contact. Let me illustrate this. 
In an experiment conducted by Seltzer, Ziegler and Pollak (2010), children were asked to participate in an activity that would for them be a stressor (a mathematics assessment). After the assessment, the children were divided into three groups. In the first group, children had direct, physical contact with their mothers. The second had telephonic contact with their mothers, while the third did not have contact with their mothers at all. In the first and second groups, mothers were asked to utter words of empathy and support, where obviously with the first group, physical contact was encouraged (e.g. a hug). The levels of oxytocin (hormone that enhances one's feeling of bonding) and cortisol (stress hormone) were then measured in each of these groups, also measuring how long it took for each of these groups to return to baseline levels of cortisol. The study showed that the first two groups had significantly higher levels of oxytocin than the third group, while it took the first two groups significantly less time to return to baseline levels of cortisol, with the third group persisting with elevated levels of cortisol for a significant amount of time after the stressor (Seltzer et al. 2010:2664-2665). The study therefore concluded that social vocalisations may increase the release of oxytocin in humans, facilitating bonding and emotional stability, while assisting with the returning to baseline levels of cortisol in a muchreduced time compared to those with no social vocalisation.

In a similar study (measuring oxytocin and cortisol levels after being exposed to a stressor and parental contact), children were divided into four groups, namely, (1) those who had direct interpersonal contact with a parent, (2) those who had no contact with a parent, (3) those who could have a telephonic conversation with their parent, and (4) those who could communicate with a parent by using an electronic messaging system. Groups 2 and 4 showed persistent high levels of cortisol, with a longer recovery time to baseline levels, with similarly low levels of oxytocin. Groups 1 and 3 showed significantly higher levels of oxytocin and a much more rapid return to baseline levels of cortisol (Seltzer et al. 2012:42-44).

Why are these experiments so important to this research question? First of all, because not only does oxytocin contribute significantly to the prevalence of empathy, but it leads to an enhanced ability of social learning, a willingness to engage with others and a reduction in social anxiety (Hurlemann et al. 2010). ${ }^{5}$ The children who had direct, physical contact with, or were exposed to vocalisations of a loved one 'recovered' and benefited much more than the groups who either had no contact or could only communicate with a parent via text. If these realities persist in the lives of these groups of children (i.e. some will have regular personal contact and/or exposed to vocalisations, while some will have little to no interaction and/or only communicate via text), then it would not only have a direct impact on their brain chemistry, but it would have significant repercussions

5.It should be noted that this study found with the administration of oxytocin therapy a marked increase in emotional empathy, but not necessarily cognitive empathy. For a marked increase in emotional empathy, but not necessarily cognitive empathy. For significance. for their social interactions and interpersonal skills. Not only this, but studies are also identifying causal links between the amount of time spent on social media and the occurrence of depressive disorders in teenagers (see Twenge et al. 2018). Kirsch et al. (2005) have shown that there is a direct relationship between having elevated levels of oxytocin on the structure and functioning of the amygdala, with the result of significantly reduced manifestations of fear, aggression and increased manifestations of positive social behaviour.

Physical presence with physical interaction and personal communication, which includes our exposure to vocalisations, verbal and non-verbal communicative cues, teach us how to exhibit pro-social behaviour.

Experience breeds experience; by experience we learn not only about who we are, but we also start developing stronger and stronger (mirror) neural pathways, enhancing our ability to engage in empathy and altruism. We need social interaction to learn how to behave in adaptive and appropriate ways (Phelps \& LeDoux 2005:183). If technology prevents or limits our social interaction, the process of developing pro-social behaviour also becomes limited. If the focus is perpetually on self, then it will be difficult for mirror neurons to be activated, resulting in increasingly hedonistic and narcissistic behaviour compared to the good life traits of empathy and altruism. The more narcissistic we become, the greater our lack of empathy (Ritter et al. 2011), and if we cannot empathise, we will most probably not be prone to altruistic behaviour.

\section{What shall we do?}

Let us first explore what we cannot do:

- We cannot just artificially make people more empathic. Studies have shown that there is no evidence to support the notion that oxytocin therapy can enhance emotional or cognitive empathy (Palgi, Klein \& Shamay-Tsoory 2017).

- We cannot ban mobile devices and the accompanying social media platforms. Although there may be a correlation between the excessive use of social media platforms and negative social behaviour, it cannot be conclusively stated that the link is causal in nature. Anyway, the technology is here to stay (and to evolve).

Although this is not an exhaustive list, I would like to offer the following practical suggestions to mediate the negative impact of social media on social behaviour, based on the insights gained from this research:

- Mindfulness: Mindfulness exercises and mindfulnessbased cognitive therapy are associated with changes in brain regions involved in, among others, emotional regulation, self-referential processing and perspective taking (Hölzel et al. 2011). Not only is it of value to persons who already exhibit pro-social behaviour, but it may also be one of the mediating tools to regulate, for instance, high levels of cortisol in persons who experience low or no levels of personal engagement. 
- Social media sabbaticals: At the time of doing research for this article, I participated in a fast during the Christian season of Lent. Being rather active on social media, I decided that for 40 days, instead of posting something about myself on social media, I would call or speak to a friend in person, relating to them the experience or thoughts I wanted to post. My own sense of bonding increased during this time and I was also able to listen to and empathise with them. Some of the sharing led to practical assistance (altruism), which also increased a sense of worth in me.

- Limiting use of personal devices: Coupled with the previous point, I have found value in limiting the use of my phone and social media platforms during certain times. To put one's phone and online life aside when sharing in family meals, while in worship, spending a few minutes of quality time with a loved one, giving undivided attention to children when they speak, these all go a long way towards strengthening relational bonds, and consequently enhance both empathy and altruism. As a parent of teenagers, I have found value in the online resources such as OurPact, Safe Kids and Screentime applications to moderate their access to and use of their personal devices and social media platforms.

- Promoting physical and interactive activities: Participation in activities such as socialising with friends, sport, exercise and spending time in nature and activities that release endorphins, norepinephrine, dopamine and serotonin all relate to regulating mood and lowering (positively moderating) stress hormones such as adrenaline and cortisol. The exposure to someone or something other than self promotes a sense of belonging to a greater system and steers one away from self-absorption.

\section{Conclusion}

This article has described the following: our sense of living a good life is grounded in the pro-social behavioural characteristics of altruism and empathy. Both these traits are promoted by religious and psychological assessments of what it means to live a good life. Although it can be accepted that technology (personal devices and accompanying social media platforms) in itself cannot ontologically cause us to be good or evil, it is worth noting that the use of technology may have a significant impact on our brain chemistry and, in turn, our behaviour. There seems to be a correlation between the high use of social media and the rise of negative social behaviour such as narcissism and bullying. Low levels of social engagement lead to high sustained levels of cortisol and low levels of oxytocin. Although we cannot artificially stimulate empathy and altruism in people, and we certainly cannot remove social media platforms from our devices, we can moderate the effect these platforms have by ensuring regular social interaction, limitations on our use thereof, taking breaks from these platforms and ensuring that we participate in activities that move the focus away from self and towards those who share this space with us.

\section{Acknowledgements Competing interests}

The author declares that they have no financial or personal relationships that may have inappropriately influenced them in writing this article.

\section{Author's contributions}

W.B.M. is the sole author of this article.

\section{Ethical considerations}

This article followed all ethical standards for carrying out research without direct contact with human or animal subjects.

\section{Funding information}

This research received no specific grant from any funding agency in the public, commercial or not-for-profit sectors.

\section{Data availability statement}

Data sharing is not applicable to this article as no new data were created or analysed in this study.

\section{Disclaimer}

The views and opinions expressed in this article are those of the author and do not necessarily reflect the official policy or position of any affiliated agency of the author.

\section{References}

Alloway, T., Runac, R., Qureshi, M. \& Kemp, G., 2014, 'Is Facebook linked to selfishness? Investigating the relationships among social media use, empathy, and narcissism', Social Networking 3(3), 150-158. https://doi.org/10.4236/sn.2014.33020

Atran, S. \& Henrich, J., 2010, 'The evolution of religion: How cognitive by-products, adaptive learning heuristics, ritual displays, and group competition generate deep commitments to prosocial religions', Biological Theory 5(1), 18-30. https://doi. org/10.1162/BIOT_a_00018

Baron, R.A., Byrne, D.R. \& Branscombe, N.R. (eds.), 2005, Social psychology, Allyn \& Bacon, Boston, MA.

Boyer, P., 2008, 'Being human: Religion: Bound to believe?', Nature 455, 1038-1039. https://doi.org/10.1038/4551038a

Brochado, S., Soares, S. \& Fraga, S., 2017, 'A scoping review on studies of cyberbullying prevalence among adolescents', Trauma Violence Abuse 18(5), 523-531. https:// doi.org/10.1177/1524838016641668

Broom, D.M., 2006, 'The evolution of morality', Applied Animal Behaviour Science 100(1), 20-28. https://doi.org/10.1016/j.applanim.2006.04.008

Clayton, P., 2011, Religion and science: The basics, Routledge, New York.

Davcevski, D., The one primary teaching of every religion, viewed 12 April 2019, from https://www.lifecoachcode.com/2017/02/02/primary-teaching-of-every-religion.

Davenport, S.W., Bergman, S.M., Bergman, J.Z. \& Fearrington, M.E., 2014, 'Twitter versus Facebook: Exploring the role of narcissism in the motives and usage of different social media platforms', Computers in Human Behaviour 32, 212-220. https://doi.org/10.1016/j.chb.2013.12.011

De Waal, F.B.M., 2008, 'Putting the altruism back into altruism: The evolution of empathy', Annual Review of Psychology 59, 279-300. https://doi.org/10.1146/ annurev.psych.59.103006.093625

Gallese, V., Eagle, M.N. \& Migone, P., 2007, 'Intentional attunement: Mirror neurons and the neural underpinnings of interpersonal relations', Journal of the American Psychoanalytic Association 55(1), 131-176. https://doi.org/10.1177/0003065107 0550010601

Heirman, W. \& Walrave, M., 2008, 'Assessing concerns and issues about the mediation of technology in cyberbullying', Cyberpsychology: Journal of Psychological Research on Cyberspace 2, 1-12.

Hölzel, B.K., Carmody, J., Vangel, M., Congleton, C., Yerramsetti, S.M., Gard, T. et al 2011, 'Mindfulness practice leads to increases in regional brain gray matter density', Psychiatry Research 191(1), 36-43. https://doi.org/10.1016/j. pscychresns.2010.08.006 
Hurlemann, R., Patin, A., Onur, O.A., Cohen, M.X., Baumgartner, T., Metzler, S. et al. 2010, 'Oxytocin enhances amygdala-dependent, socially reinforced learning and
emotional empathy in humans', Journal of Neuroscience 30(14), 4999-5007. https://doi.org/10.1523/JNEUROSCI.5538-09.2010

Iacoboni, M., 2009, 'Imitation, empathy, and mirror neurons', Annual Review of Psychology 60, 653-670. https://doi.org/10.1146/annurev.psych.60.110707. 163604

Keysers, C., 2011, The empathic brain, Social Brain Press, Lexington, KY.

Kirsch, P., Esslinger, C., Chen, Q., Mier, D., Lis, S., Siddhanti, S. et al., 2005, 'Oxytocin modulates neural circuitry for social cognition and fear in humans', Journal of Neuroscience 25(49), 11489-11493. https://doi.org/10.1523/JNEUROSCI.398405.2005

Kretzschmar, L., Bentley, W. \& Van Niekerk, A. (eds.), 2009, What is a good life? An introduction to Christian ethics in 21st century Africa, AcadSA Publishing, Kempton Park.

Leung, L., 2013, 'Generational differences in content generation in social media: The roles of the gratifications sought and of narcissism', Computers in Human Behaviour 29(3), 997-1006. https://doi.org/10.1016/j.chb.2012.12.028

Palgi, S., Klein, E. \& Shamay-Tsoory, S., 2017, 'The role of oxytocin in empathy in PTSD', Psychological Trauma 9(1), 70-75. https://doi.org/10.1037/ tra0000142

Phelps, E.A. \& LeDoux, J.E., 2005, 'Contributions of the amygdala to emotion processing: From animal models to human behavior', Neuron 48(2), 175-187. https://doi.org/10.1016/j.neuron.2005.09.025
Richardson, N., 2009, 'Morality and community in Africa', in L. Kretzschmar, W. Bentley \& A. Van Niekerk (eds.), What is a good life? An introduction to Christian ethics in 21st century Africa, pp. 43-56, AcadSA Publishing, Kempton Park.

Ritter, K., Dziobek, I., Preissler, S., Rüter, A., Vater, A., Fydrich, T. et al., 2011, 'Lack of empathy in patients with narcissistic personality disorder', Psychiatry Research 187(1), 241-247. https://doi.org/10.1016/j.psychres.2010.09.013

Seltzer, L.J., Prososki, A.R., Ziegler, T.E. \& Pollak, S.D., 2012, 'Instant messages vs. speech: Hormones and why we still need to hear each other', Evolution and Human Behavior 33(1), 42-45. https://doi.org/10.1016/j.evolhumbehav.2011.05.004

Seltzer, L.J., Ziegler, T.E. \& Pollak, S.D., 2010, 'Social vocalizations can release oxytocin in humans', Proceedings of the Royal Society 277, 2661-2666. https://doi.org/ 10.1098/rspb.2010.0567

Twenge, J.M. \& Campbell, W.K., 2009, The narcissism epidemic: Living in the age of entitlement, Simon and Schuster, New York.

Twenge, J.M., Joiner, T.E., Martin, G. \& Rogers, M.L., 2018, 'Digital media may explain a substantial portion of the rise in depressive symptoms among adolescent girls: Response to Daly', Clinical Psychology 6(3), 296-297. https://doi.org/10.1177/ 2167702618759321

University of Würzburg, 2017, Narcissism and social networking, viewed 07 May 2019, from https://www.sciencedaily.com/releases/2017/04/170418094255.htm.

Wertz, J., Caspi, A., Belsky, D.W., Beckley, A.L., Arseneault, L., Barnes, J.C. et al., 2018, 'Genetics and crime: Integrating new genomic discoveries into psychological
research about antisocial behavior', Psychological Science 29(5), 791-803. https:// doi.org/10.1177/0956797617744542 